\title{
Comparative Study of Partitioned Stator Permanent Magnet Tubular Machines with Different Winding Configurations
}

\author{
Ahlam Luaibi Shuraiji ${ }^{1}$, Z.Q. Zhu ${ }^{2}$ \\ ${ }^{I}$ Department of Electromagnetic Engineering, University of Technology, Baghdad, Iraqi, email \\ ahlamly2009@yahoo.com, ${ }^{2}$ Department of Electronic and Electrical Engineering, University of Sheffield, \\ Sheffield, S1 4DE, UK, email z.q.zhu@ sheffield.ac.uk
}

\begin{abstract}
In this study, partitioned stator permanent magnet (PS-PM) tubular machines having single- and double-layer windings layouts have been investigated. Two configurations of PS-PM tubular machines were considered, i.e. partitioned stator surface mounted permanent magnet (PS-SPM) and interior permanent magnet (PS-IPM) tubular machines. A comprehensive comparison has been carried out in order to investigate the impact of the winding layouts on such machines. It should be mentioned that the FE package that is used in this paper is (ANSYS Maxwell). It has been noted that irrespective of machines configurations, i.e. either PS-SPM or PS-IPM tubular machines, similar thrust force capability, higher average thrust force per magnet volume, lower thrust force ripple as well as cogging force and higher fault tolerance capability can be delivered by PS-PM tubular machines with single-layer winding compared to that with double-layer winding.
\end{abstract}

Index Terms - Permanent magnet machines, single and double-layer windings, Tubular machines

\section{INTRODUCTION}

Partitioned stator permanent magnet (PS-PM) machines have recently been introduced to tackle the compromising between electrical and magnetic loadings in conventional double salient permanent magnet (DSPM) machines, such as switched flux permanent magnet (SFPM) machines and flux reversal permanent magnet (FRPM) machines [1]-[4]. It is worth mentioning that PS-PM machines have been designed with rotary and linear configurations [5]-[10]. The interest in PM linear machines has been increased, as they have particular features compared to their rotary corresponding [11].

Generally, linear machines can be classified into three main topologies including.

- Flat linear machines.

- Tubular machines.

- Short stroke single phase tubular machines.

Among these three configurations, tubular machines have been of interest due to the fact that such topologies possess the advantages of no end windings effect and zero net attractive force [12]-[13].

PS-PM tubular machines were introduced in [10]. Two configurations of PM tubular machines were designed, i.e. partitioned stator surface mounted permanent magnet (PSSPM) and interior permanent magnet (PS-IPM) tubular machines. The machines structures and operating principle are explained. A comparison between such machines were carried out. It was shown that higher flux linkage and back-EMF, consequently higher thrust force 
capability can be delivered by PS-IPM tubular machine compared to the PS-SPM counterpart. In this study the influence of the winding layouts on the mentioned machines will be investigated. The rest of this paper is organized as follows: the configurations of PSSPM tubular machines having single- and double-layer windings are explained in section 2.1. On the other hand, no-load and load performances of such machines are compared in sections 2.2 and 2.3, respectively. In addition, section 3.1 presents the structures of both PSIPM tubular machines with single- and double-layer windings. Moreover, comparisons of no-load and load performances of these machines are carried out in sections 3.2 and 3.3, respectively. It is worth mentioning that $2 \mathrm{D}$-axi-symmetric $\mathrm{FE}$ simulation has been utilized to design, optimize and analyse the understudying machines.

\section{PS-SPM TUBULAR MACHINES}

\section{A. Machines configurations}

In order to obtain a PS-SPM tubular machine with a single-layer winding configuration, the double-layer windings PS-SPM tubular machine has been redesigned. The construction difference between both machines can be observed in Fig. 1. Obviously, the PS-SPM tubular machine with double-layer winding has an empty half slot at each end, which is created by the assistance teeth. On the other hand, the configuration of single-layer tubular machine eliminates the need of such slots. Therefore, the single-layer tubular machine has been designed with one slot pitch less than that of its double-layer counterpart. Furthermore, to carry out a fair comparison between both machines, the single-layer machine is designed with the same specifications of the double-layer machine, which can be found in Appendix A.

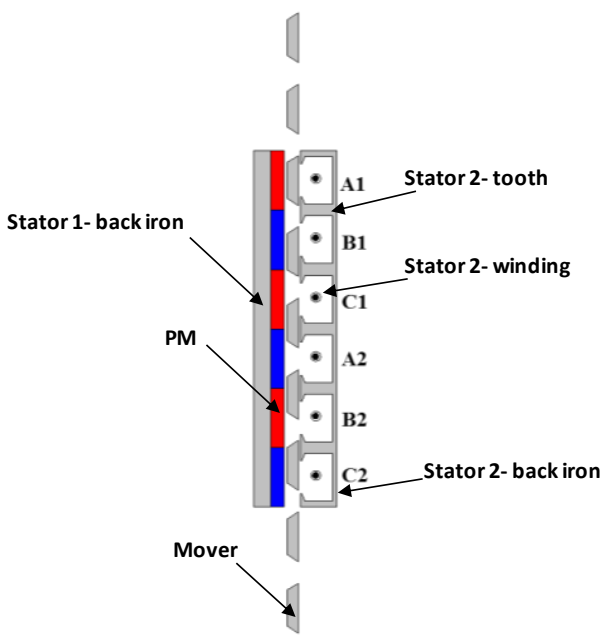

(A) 2D-VIEW TUBULAR SL-PS-SPM

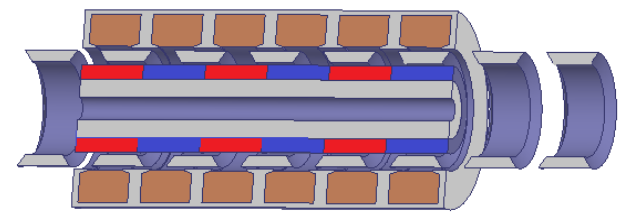

(c) 3D-VIEW TUBULAR SL-PS-SPM

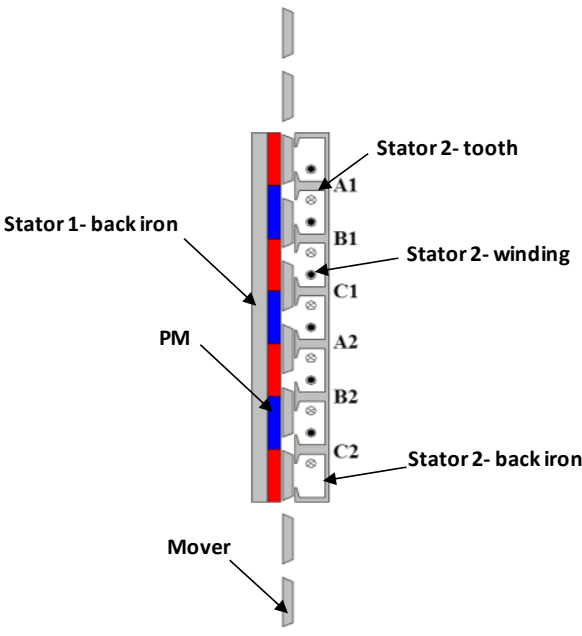

(B) 2D-VIEW TUBULAR DL-PS-SPM

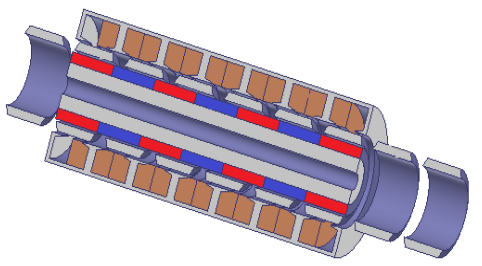

(B) 3D-VIEW TUBULAR DL-PS-SPM

FIG. 1 CROSS-SECTION OF BOTH SINGLE-AND DOUBLE-LAYER WINDINGS. 


\section{B. No-load Performance comparison}

Phase A flux linkages in both machines are compared in Fig. 2. However, both machines exhibit asymmetric flux linkage due to the presence of the longitudinal end, the single-layer machine has a higher DC component compared to the double layer machine. The impact of the longitudinal end effect can be explained by comparing the flux linkage of the practical model (with longitudinal end effect) with the periodic model (without longitudinal end effect), as it is shown in Fig. 2.

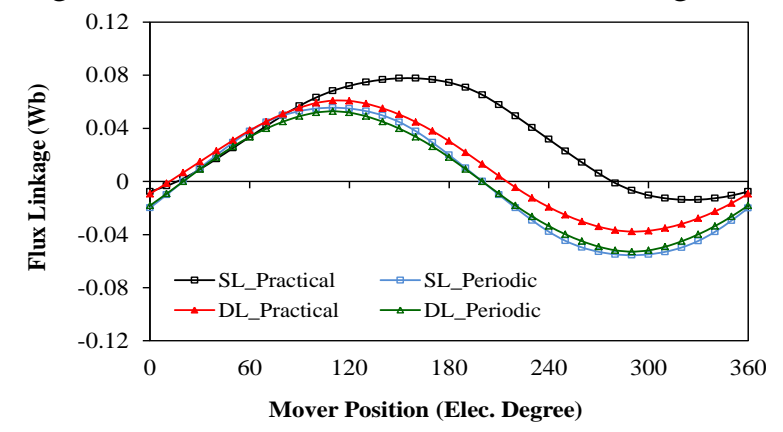

(A) WAVEFORM

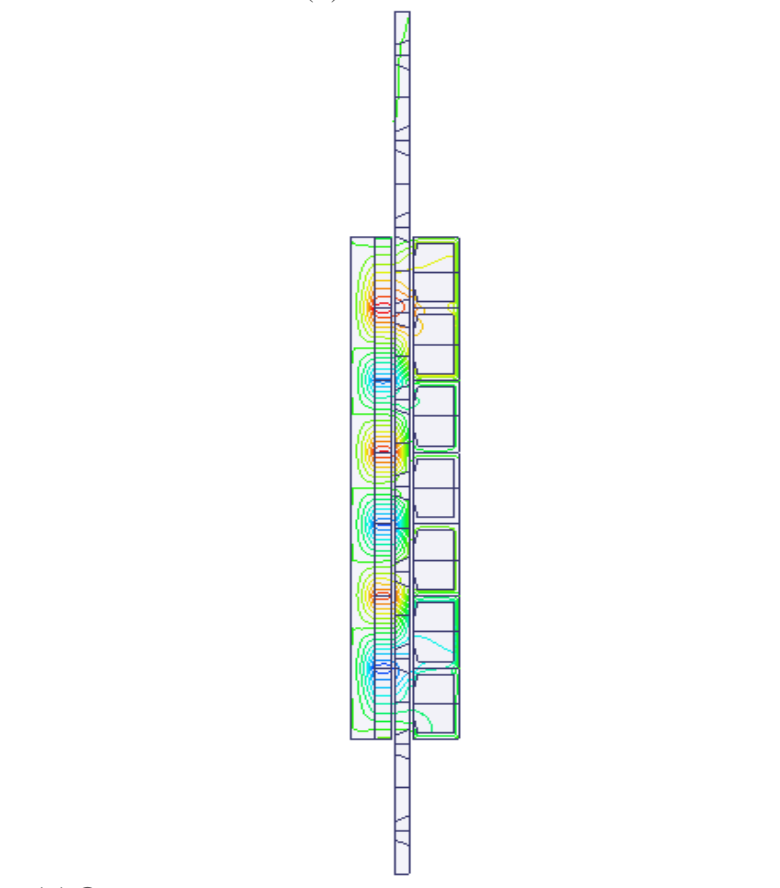

(C) OPEN-CIRCUIT FLUX LINE DISTRIBUTION -DOUBLE-LAYER

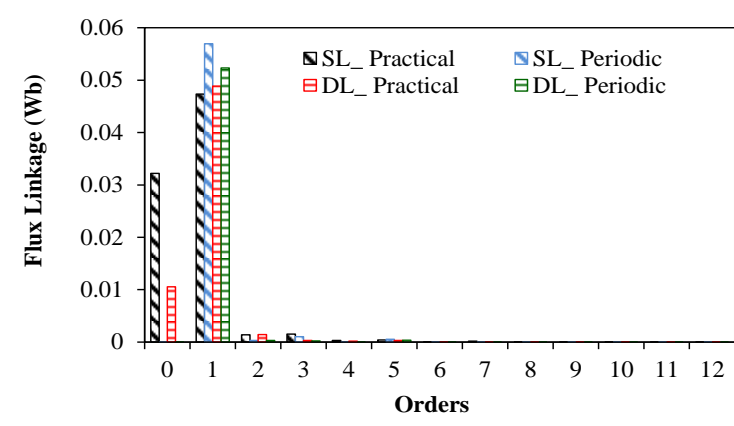

(B) SPECTRUM

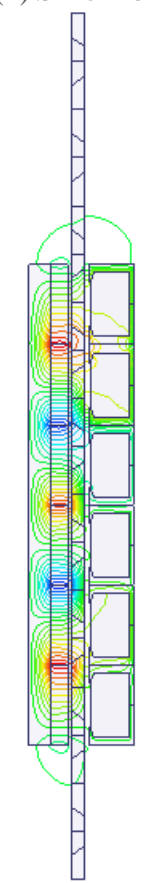

(D) OPEN-CIRCUIT FLUX LINE DISTRIBUTION -SINGLE-LAYER

\section{Fig. 2 PHASE A FluX LINKAGE COMPARISON.}

The periodic models of both single- and double- layer windings machines have symmetry flux linkage, while the practical models deliver asymmetry flux linkage. On the other hand, coil flux linkages can be employed to illustrate the difference between the flux linkages of two machines. Fig. 3 and Fig. 4 depict phase A coil flux linkages for single- and double-layer windings machines, respectively. It can be seen that four coils contribute to the phase flux linkage of the double layer-windings machine and only coil A1 has unipolar flux linkage. Thus, the DC component can be reduced when adding the coil flux linkages together. In contrast, the phase flux linkage of the single-layer windings machine comprises of two coils, i.e. coil A1 with unipolar flux linkage and coil A2 with bipolar flux linkage, which also has a DC component. Therefore, the DC component of the result in phase flux linkage would be increased when adding these coils together. Phase A back-EMFs for both 
machines are shown in Fig.5. Considering the longitudinal end effect, the double-layer winding machine has slightly higher back-EMF compared to that of the single-layer windings machine; otherwise, the periodic model of the single-layer winding machine shows higher back-EMF than that of the double-layer winding machine.

Fig. 6 compares cogging forces for both machines. Generally, changing the winding configuration from single-layer to double-layer and vice versa does not have any impact on the machine cogging force/torque, if the machine structure is not changed. However, as mentioned above, the structures of the understudying machines are different. Thus, it is worth comparing the cogging force in both machines. Clearly, the single-layer winding machine has a lower cogging force compared to that of the double-layer winding machine.

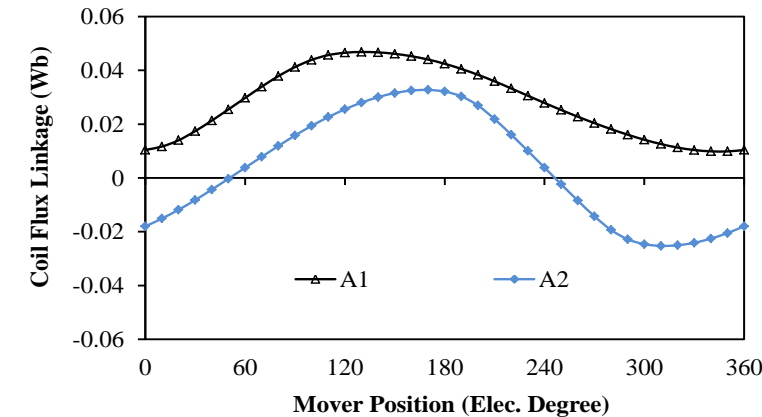

(A) WAVEFORM

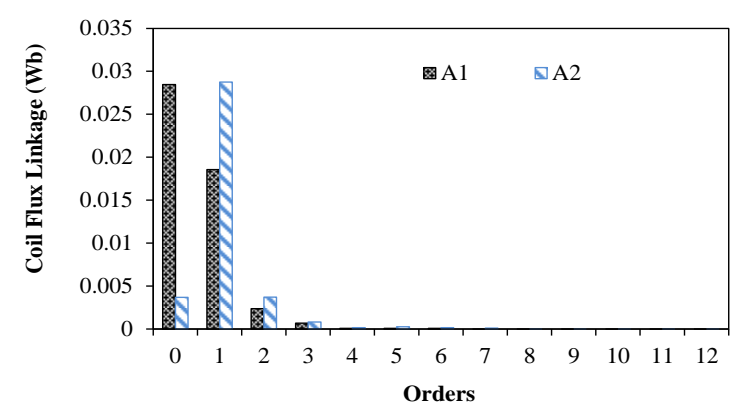

(B) SPECTRUM

FIG. 3 COIL FLUX LINKAGE IN SINGLE-LAYER WINDING MACHINE.

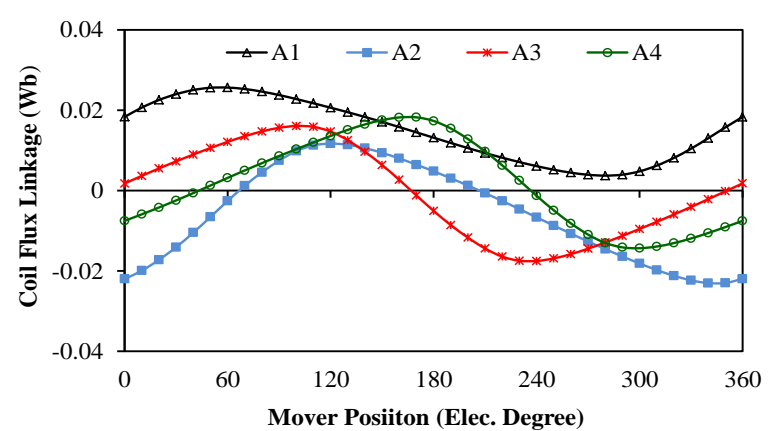

(A) WAVEFORM

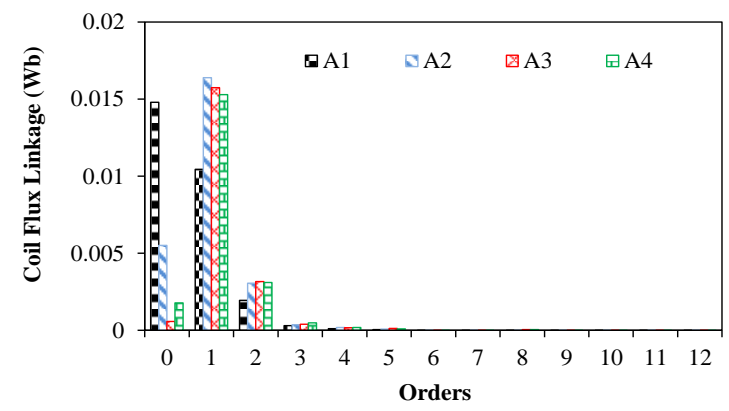

(B) SPECTRUM

FIG. 4 COIL FLUX LINKAGE IN DOUBLE-LAYER WINDING MACHINE.

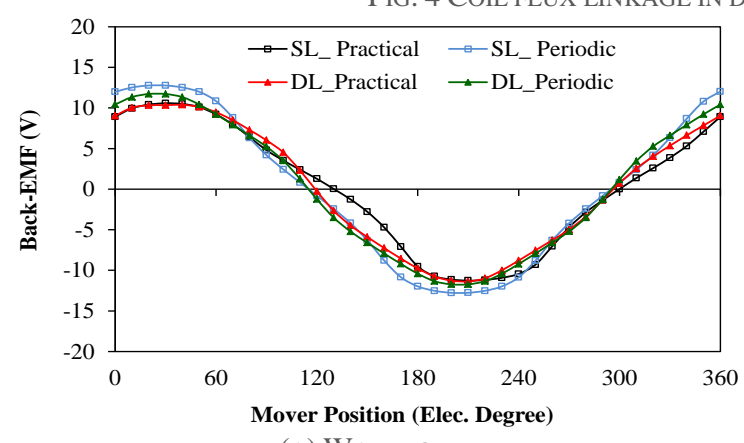

(A) WAVEFORM

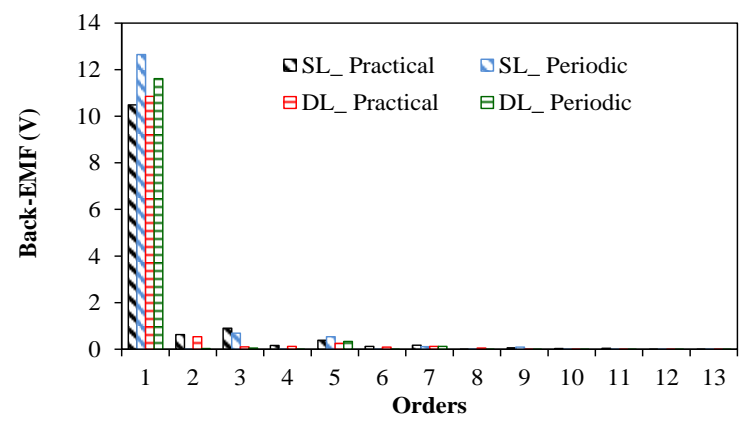

(B) SPECTRUM

Fig. 5 PHASE A BACK-EMF COMPARISON. 


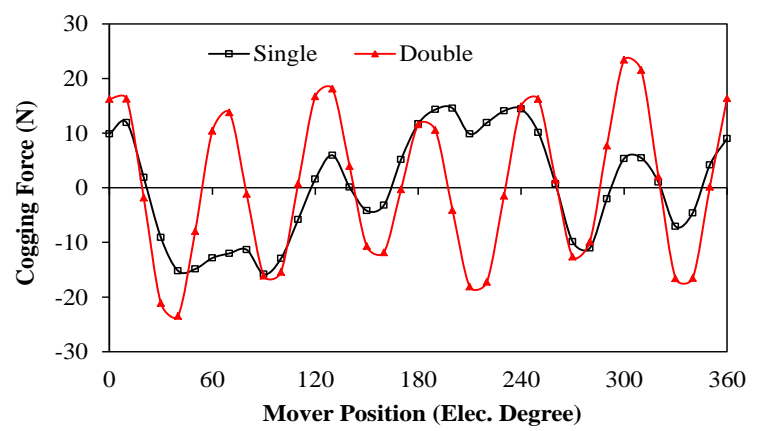

FIG. 6 COGGING FORCE COMPARISON.

\section{Load Performance comparison}

The variations of the average thrust force with copper loss for both machines are illustrated in Fig. 7. However, the amount of magnet usage in a single-layer machine is less than that of a double-layer machine. Both machines produce similar thrust force at lower copper loss value while at high copper loss value the single-layer winding machine exhibits slightly higher thrust force than that of the double-layer winding. Moreover, the variations of thrust forces with mover position and different copper losses for both machines are displayed in Fig. 8 and Fig. 9. Furthermore, the variations of average thrust force per total magnet volume with copper loss for both machines are illustrated in Fig. 10. It can be seen that the single layer-winding machine has better magnet utilization than that of the doublelayer winding machine. On the other hand, thrust force ripples of both understudying machines are shown in Fig. 11. Obviously, lower thrust force ripple is for PS-SPM tubular machine with the single-layer winding configuration.

Self and mutual inductances for both machines are compared in Fig. 12. It can be observed that the double-layer winding machine exhibits lower self-inductance compared with that of the single-layer winding. It should be mentioned that the ratio of mutual to selfinductance of the double-layer winding machine is less than that of the single-layer winding machine. Thereby, the single-layer winding machine can deliver more fault tolerance capability, since it possesses less coupling compared to the double-layer machine [14].

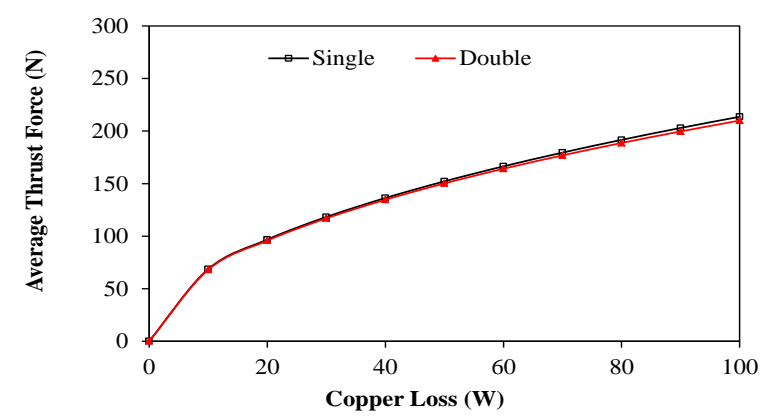

FIG. 7 AVERAGE THRUST FORCE VARIATION WITH COPPER LOSS.

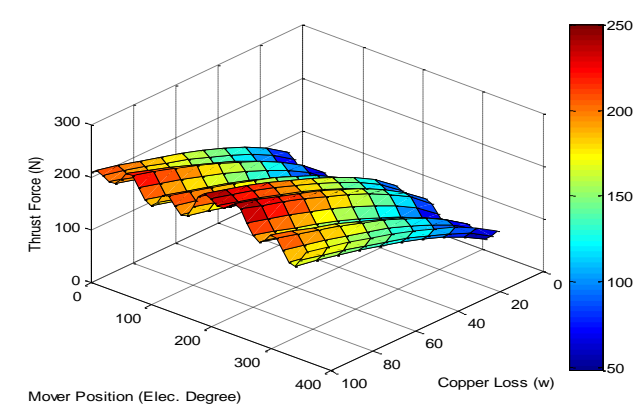

FIG. 8 TUBULAR SL- PS-SPM THRUST FORCE VARIATION WITH MOVER POSITION AND COPPER LOSS. 


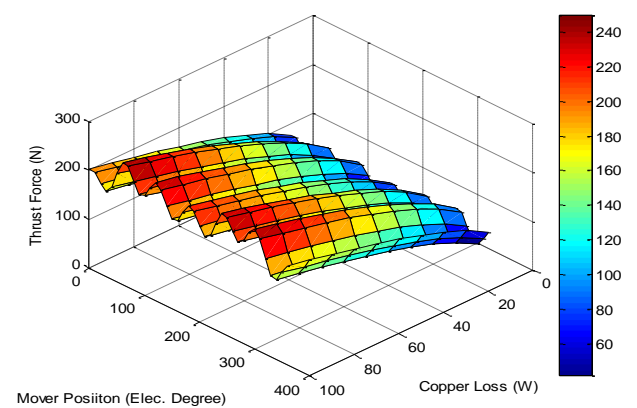

FIG. 9 TUBULAR DL- PS-SPM THRUST FORCE VARIATION WITH MOVER POSITION AND COPPER LOSS.

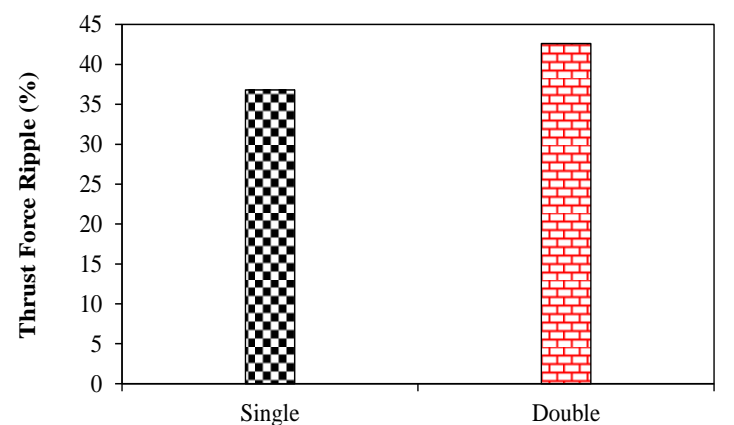

FIG. 11 THRUST FORCE RIPPLE COMPARISON.

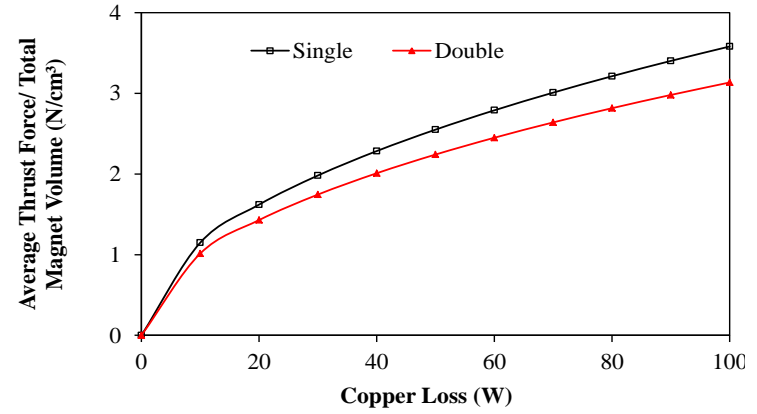

FIG. 10 PM UTILIZATION COMPARISON.

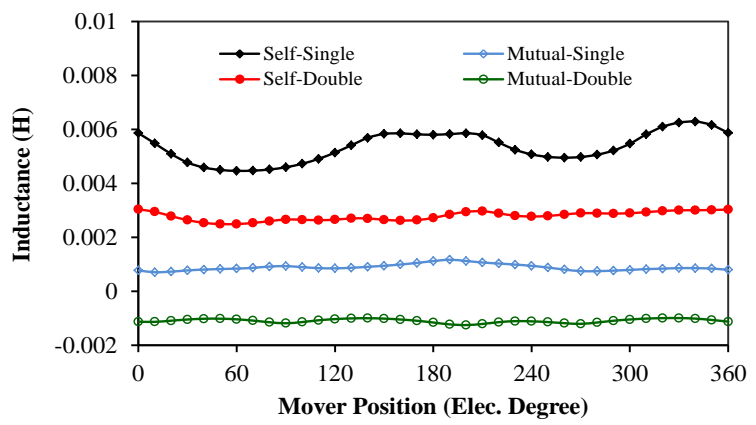

FIG. 12 SELF- AND MUTUAL-INDUCTANCES COMPARISON.

\section{PS-IPM TUBULAR MACHINES}

\section{A. Machines configurations}

PS-IPM tubular machines having double-layer and single-layer winding configurations will be compared in terms of no-load and load performance. It should be mentioned that the PS-IPM tubular machine with single-layer configuration has been designed with the same main design parameters to that of the double-layer counterpart, which are listed in Appendix A. Machine configurations are depicted in Fig. 13. Obviously, PS-IPM with single-layer winding has one coil per slot, whilst the doubly-layer winding counterpart has two coils which belong to different phases per one slot.

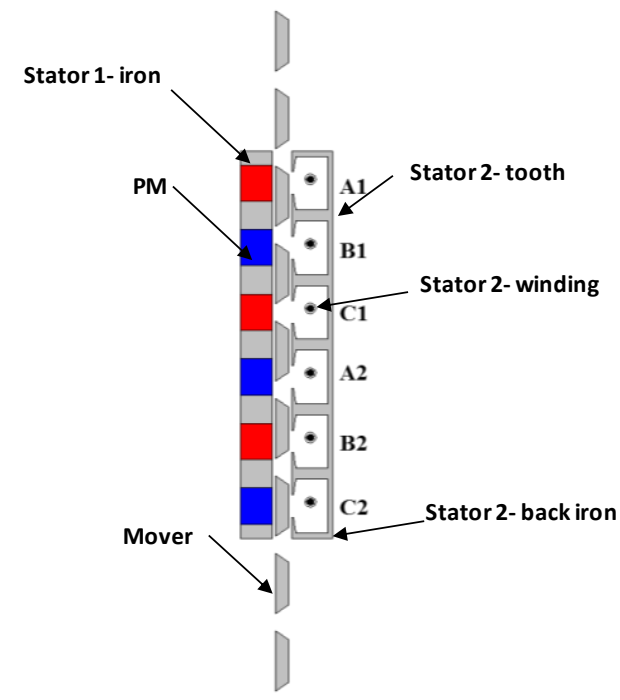

(A) 2D-VIEW OF TUBULAR SL-PS-IPM

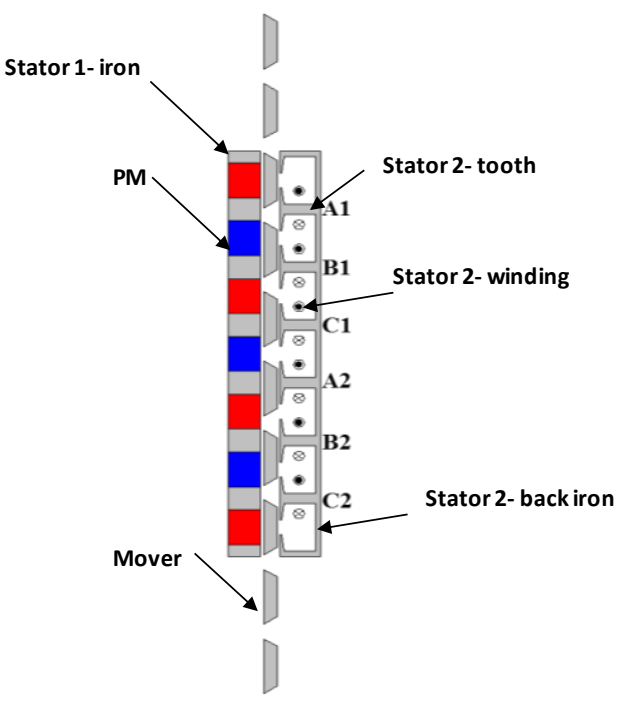

(в) 2D-VIEW OF TUBULAR DL-PS-IPM 


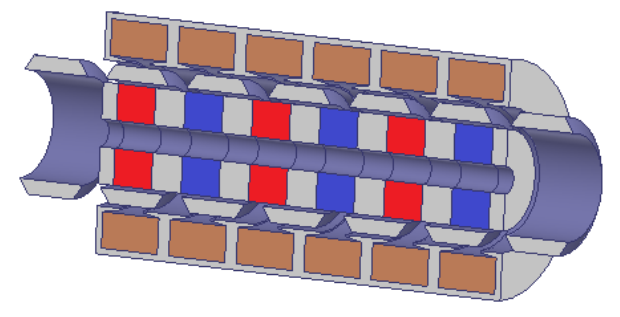

(C) 3D-VIEW OF TUBULAR SL-PS-IPM

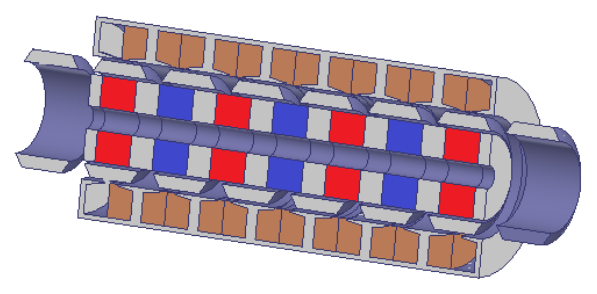

(D) 3D-VIEW OF TUBULAR DL-PS-IPM

FIG. 13 CROSS-SECTION OF BOTH SINGLE-AND DOUBLE-LAYER WINDINGS.

\section{B. No-load Performance comparison}

Phase A flux linkages and back-EMFs for both machines are compared in Fig. 14 and Fig. 15, respectively. It can be noted that the single-layer winding machine shows about $8 \%$ higher flux linkage and back-EMF compared to the double-layer winding machine, due to the higher winding factor.

Fig. 16 compares cogging force for both machines. Usually, winding configuration (single- and double-layers) has no effect on the machine cogging torque/force when the machine structure is not changed. As mentioned in the previous section, for tubular machines, the structures of single- and double- layer windings are not the same, when an assistance teeth configuration is employed. Hence, it would be beneficial to compare the cogging force in both machines. It can be seen that the single-layer winding machine exhibits lower cogging force compared to its double-layer winding counterpart.

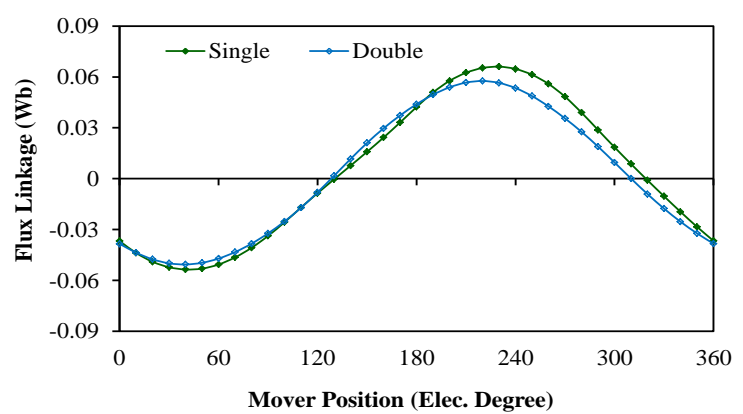

(A) WAVEFORM

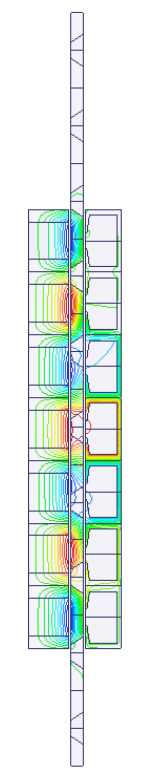

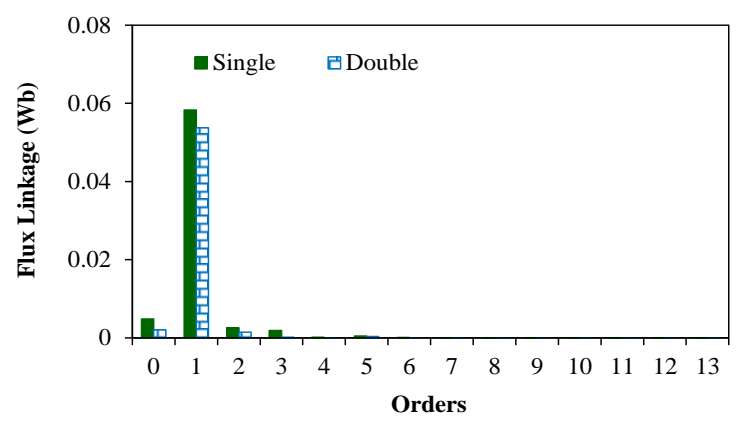

(B) SPECTRUM

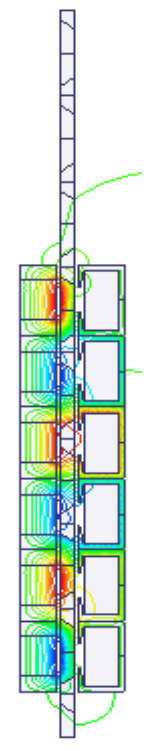

(D) OPEN-CIRCUIT FLUX LINE DISTRIBUTION -SINGLE-LAYER LINKAGE COMPARISON 


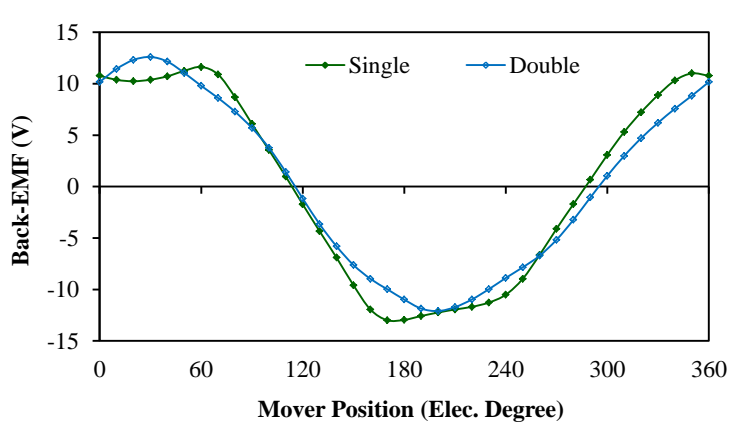

(A) WAVEFORM

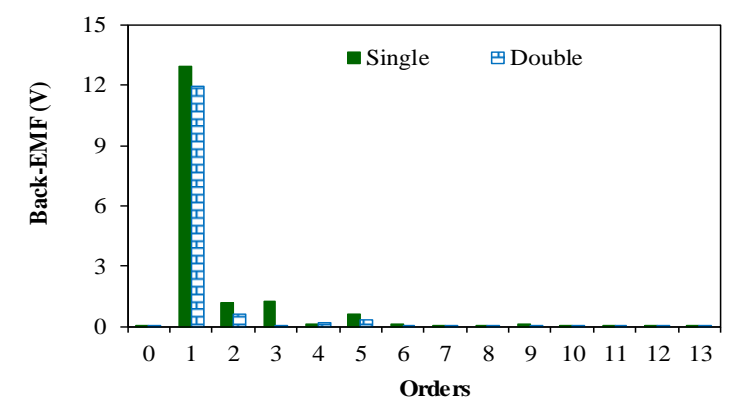

(B) SPECTRUM

FIG. 15 PHASE A BACK-EMF COMPARISON

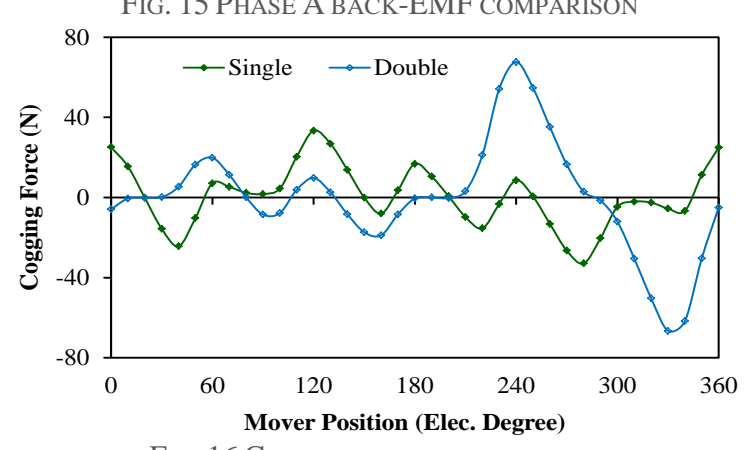

FIG. 16 COGGING FORCE COMPARISON

\section{Load Performance comparison}

Average thrust force variations with the copper loss for both machines are shown in Fig. 17. Apparently, the PS-IPM tubular machine with single-layer windings has slightly higher average thrust force than that with double-layer windings, due to higher back-EMF. Thrust force variation with mover position and different copper losses for both understudying machines are shown in Fig. 18 and Fig. 19. Additionally, thrust forces per magnet volume with different copper losses for the understudying machines are illustrated in Fig. 20. Higher average thrust force per magnet volume can be delivered by a singlelayer winding machine, and thus, such configuration has better magnet usage compared to a double-layer winding machine. Furthermore, Fig. 21 compares thrust force ripple for both machines. It can be noted that tubular PS-IPM machine with single layer-winding has lower thrust fore ripple than that of double-layer winding corresponding. Moreover, the predicted winding inductances including self- and mutual inductances for the aforementioned machines are presented in Fig. 22. Notably, the PS-IPM tubular machine with single-layer configuration possesses higher self- inductance and lower mutual- to self-inductance ratio in comparison with its double-layer winding counterpart.

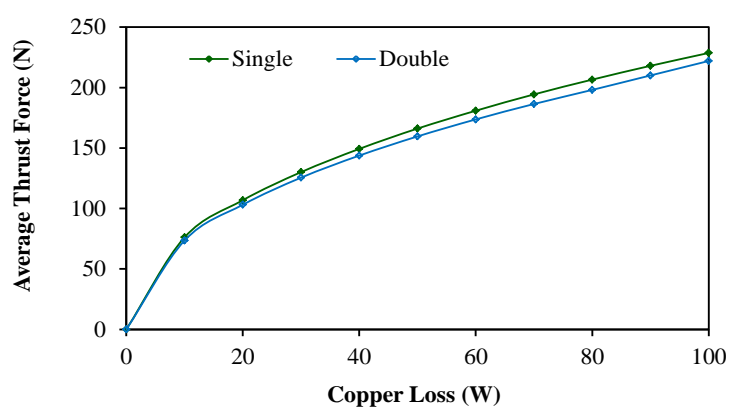

FIG. 17 AVERAGE THRUST FORCE VARIATION WITH COPPER LOSS

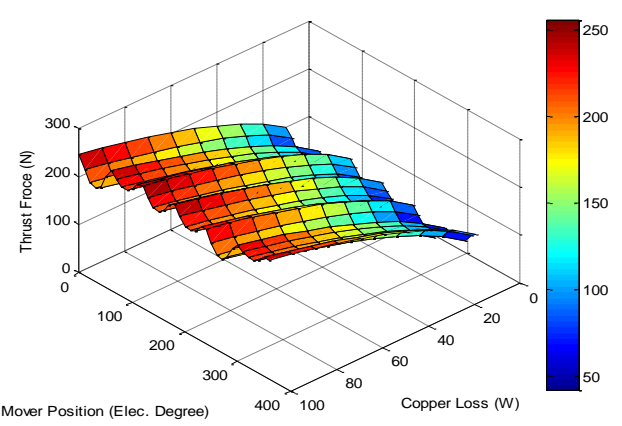

FIG. 18 TUBULAR SL- PS-IPM THRUST FORCE VARIATION WITH MOVER POSITION AND COPPER LOSS 


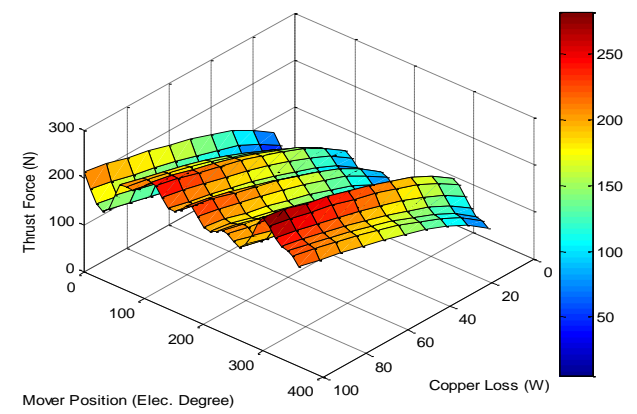

FIG. 19 TUBULAR DL- PS-IPM THRUST FORCE VARIATION WITH MOVER POSITION AND COPPER LOSS.

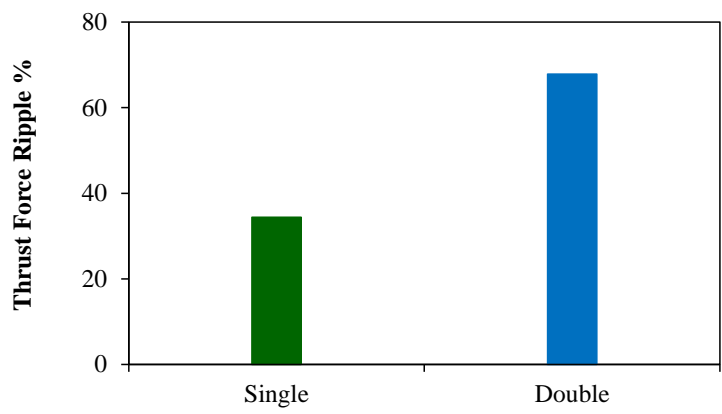

FIG. 21 THRUST FORCE RIPPLE COMPARISON.

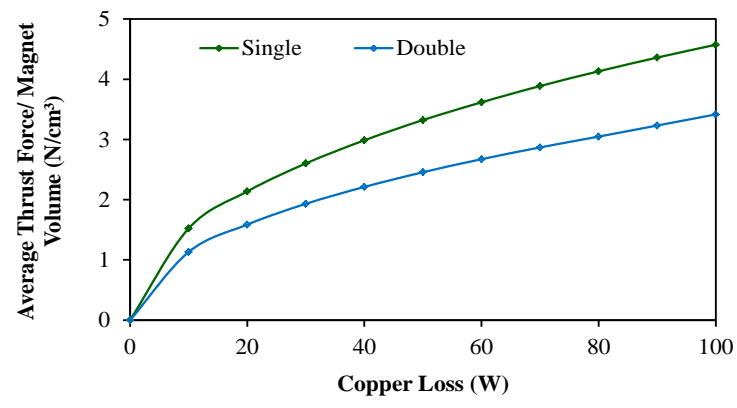

FIG. 20 PM UTILIZATION COMPARISON

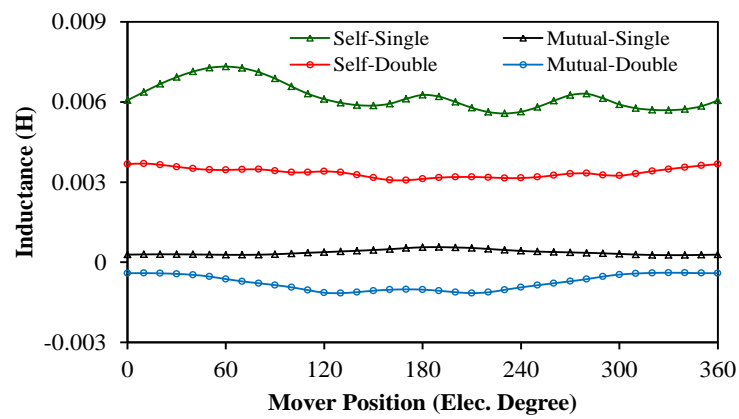

FIG. 22 COMPARISON OF SELF- AND MUTUAL-INDUCTANCES.

\section{CONCLUSION}

The influence of winding configuration on the performance of the PS-PM tubular machines has been investigated. Two configurations of PS-PM tubular machines, i.e., PSSPM and PS-IPM tubular machines are considered. The machines configurations are compared. No-load as well as load performances of the understudying machines are analysed using 2D-axi-symmetric FE simulation, and compared. It is found that the PS-PM tubular machines with single layer winding configuration show similar thrust force capability, better PM utilization, higher self- inductance and lower mutual- to selfinductance ratio, and lower cogging fore, consequently lower thrust force ripple compared to double-layer winding configuration counterparts. On the other hand, despite the fact that both PS-PM tubular machines with single- and double-layer windings configurations have asymmetry flux linkage, the single-layer configuration machines exhibit higher DC component than that of the double-layer winding machines.

\section{REFERENCES}

[1] D. J. Evans and Z. Q. Zhu, "Novel partitioned stator switched flux permanent magnet machines," IEEE Trans. Magnetics, vol. 51, no. 1, pp. 1-14, January, 2015.

[2] Z. Z. Wu, Z. Q. Zhu and J. T. Shi, "Novel Doubly Salient Permanent Magnet Machines with Partitioned Stator and Iron Pieces Rotor," IEEE Trans. Magnetics, vol. 51, no. 5, pp. 1-12, May 2015.

[3] Z. Q. Zhu, Z. Z. Wu, D.J. Evans, and W. Q. Chu, "Novel electrical machines having separate PM excitation stator," IEEE Trans. Magnetics, vol.51, no.4, pp.1-9, April, 2015.

[4] Z. Z. Wu and Z. Q. Zhu, "Partitioned Stator Flux Reversal Machine with Consequent-Pole PM Stator," IEEE Trans. Energy Conversion, vol. 30, no. 4, pp. 1472-1482, Dec. 2015.

[5] Z. Wu; Z. Zhu, "Comparative analysis of end effect in partitioned stator flux reversal machines having surface-mounted and consequent pole permanent magnets," IEEE Trans. Magnetics, no.99, pp.1-1, July, 2016.

[6] Z. Q. Zhu, H. Hua, D. Wu, J. T. Shi and Z. Z. Wu, "Comparative study of partitioned stator machines with different pm excitation stators," IEEE Trans. Industry Applications, vol. 52, no. 1, pp. 199-208, January, 2016.

[7] A. L. Shuraiji, Z. Q. Zhu and Q. F. Lu, "A novel partitioned stator flux reversal permanent magnet linear machine," IEEE Trans. Magnetics, vol. 52, no. 1, pp. 1-6, Jan. 2016.

[8] Q. Lu, J. Shi, X. Huang, Y. Fang and Y. Ye, "Performance of partitioned primary linear switched flux PM machines," in Proc. on Electrical Machines Int. Conf., pp. 2486-2491, 2016 
[9] A. L. Shuraiji, Z. Q. Zhu and Q. F. Lu, "Comparative study of different doubly salient PM tubular machine topologies," The eighth International Conference on Power Electronic, Machines and Drives (PEMD16), April 19-21, Glasgow, Scotland, UK.

[10] Z. Q. Zhu, A. L. Shuraiji and Q. F. Lu, "Comparative study of tubular partitioned stator permanent magnet machines," IEEE Trans. Magnetics, vol. 52, no. 1, pp. 1-7, Jan. 2016.

[11] R. Cao, M. Cheng and W. Hua, "Investigation and general design principle of a new series of complementary and modular linear FSPM motors," IEEE Trans. Industrial Electronics, vol.60, no.12, pp.5436-5446, December 2013.

[12] N. Bianchi, S. Bolognani, D. Corte, and Tonel, "Tubular linear permanent magnet motors: An overall comparison," IEEE Trans. Industry Applications, vol.39, no.2, pp. 466-475, March, 2003.

[13] J. B. Wang, and D. Howe, "Influence of soft magnetic materials on the design and performance of tubular permanent magnet machines," IEEE Trans. Magnetics, vol. 41, no. 10, pp. 4057-4059, October, 2005.

[14] N. Bianchi, S. Bolognani, M. D. Pre and G. Grezzani, "Design considerations for fractional-slot winding configurations of synchronous machines,” IEEE Trans. Industrial Applications, vol.42, no.4, pp.997-1006, July, 2006.

[15] C. C. Awah et al., "Comparison of Partitioned Stator Switched Flux Permanent Magnet Machines Having Single- or Double-Layer Windings," IEEE Trans. Magnetics, vol. 52, no. 1, pp. 1-10, Jan. 2016.

\section{APPENDIX}

\section{Machines configuration and operating principle}

It can be noted from Fig. 1 and Fig. 13 that the machines have a mover made of iron only and two stators. The phase's windings are hosted on the outer stator, while the permanent magnets are located on the inner stator possess (i.e. mounted on the inner stator surface for SPM topology and buried in the inner stator iron for IPM topology). The main design specifications of the understudying machines are listed in Table 1. The operation principle of the understudying machines is based on the flux switching principle, where both magnitude and direction of flux are chaining with mover position. Fig. 1 shows four positions of mover in which the flux linkage of phase $A$ is changing from maximum positive, zero, maximum negative and zero. On position (1), maximum positive value of flux linkage will be obtained, and the flux linkage becomes zero on position (b). Then, it reaches the maximum negative value on position (c), after that the flux linkage of the armature windings is zero on position (d). On load condition, thrust force is produced by the interaction between the PM flux and the armature current flux.

TABLE 1 DESIGN PARAMETERS OF UNDERSTUDYING MACHINES.

\begin{tabular}{cc}
\hline Items & $\begin{array}{c}\text { PS-SPM/PS-IPM (double-layer winding) and PS-SPM/PS-IPM } \\
\text { (single-layer winding) }\end{array}$ \\
\hline Number of phases & 3 \\
Number of mover poles & 5 \\
Number of stator slots & 6 \\
Outer stator slot pitch & $23.6 \mathrm{~mm}$ \\
Inner stator slot pitch & $23.6 \mathrm{~mm}$ \\
Mover pole pitch & $28.32 \mathrm{~mm}$ \\
Outer air gap radial length (GO) & $1 \mathrm{~mm}$ \\
Inner air gap radial length (GI) & $1 \mathrm{~mm}$ \\
Outer stator radius (OSR) & $35 \mathrm{~mm}$ \\
Inner stator radius (ISR) & $13.5 \mathrm{~mm}$ \\
Mover radius (MR) & $19.5 \mathrm{~mm}$ \\
\hline
\end{tabular}



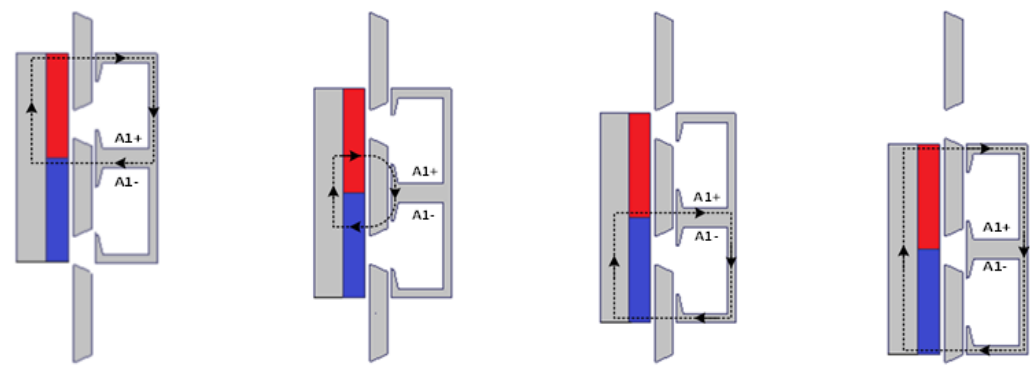

position [a]

position [b]

position [c]

position [d]

FIG. 1 SCHEMATICS OF OPERATION PRINCIPLE FOR PROPOSED TUBULAR MACHINES. 